\title{
Die betekenis van ds. Dirk Postma se bevordering van Christelike onderwys vir negentiende-eeuse Nederland en vir Suid-Afrika vandag
}

\author{
W. Postma \\ Departement Fundamentele en Historiese Opvoedkunde \\ Potchefstroomse Universiteit vir CHO \\ POTCHEFSTROOM
}

\begin{abstract}
The Rev. Dirk Postma was not only the founder of the Reformed Church of South Africa (Ciereforncerde Kerk), but also made significant contributions in the field of education. In this aricle the leading role he played with regard to the promotion of Christian cducation in the Netherlands (1848-1859) and in South Africa (1859-1890) is outlined. He was responsible for the establishment of the first Christian school in Zwolle and his dynamic involvement in education in South Africa had the result, among others, that the Potchefstroom University for Christian Higher Education came into being. His worthwhile activities in the senvice of Christian education are an example for present-day Christian educators in South Africa to tackle the educational problems which are rife at present and possibly to solve them in a like manter.
\end{abstract}

\section{INLEIDING}

Dit is welbekend watter deurslaggewende aandeel ds. Dirk Postma in die stigting en die vestiging van die Gereformeerde Kerk hier in Suid-Afrika gehad het. Verskeie skrywers (Van der Vyver, 1958, Bingle, 1954 en Postma, 1944) verleen erkenning aan die feit dat ds. Postma hom hier te lande ten volle ingewerp het ter bevordering van Christelike onderwys (vergelyk paragraaf 5).

Wat egter minder bekend is, is Postma se stryd ter bevordering van Christelike onderwys ("bijzondere onderwijs") in Nederland. Bibliografiese navorsing in verskeie biblioteke en argiewe in Suid-Afrika het weinig inligting aangaande Postma se onderwysgerigte arbeid in Nederland opgelewer. Gevolglik is ondersoek in Nederland self ingestel waar hy in die negentiende eeu as predikant en as kampvegter vir Christelike onderwys waardevolle werk verrig het.

Gedagtig aan die nood waarin die onderwys van Suid-Afrika tans verkeer, asook aan die behoefte aan Christelike onderwys, is dit raadsaam om evaluerend na Postma se opvoedende onderwysbetrokkenheid in Nederland en in Suid-Afrika te kyk. Sodoende 
kan daar moontlik wins vir die huidige Suid-Afrikaanse onderwys verkry word uit Postma se bydraes vir die destydse Christelike onderwys.

Die probleemurae wat dus aan die orde kom, is: Wat was Postma se bydrae tot Christelike onderwys in Nederland en in Suid-Afrika en van watter betekenis is hierdie bydrae vir die huidige en toekomstige Suid-Afrikaanse onderwys?

Om hierdie probleemvrae te probeer beantwoord, sal van die volgende werkwyse gebruik gemaak word:

* Eerstens sal vasgestel word teen watter kultuur-historiese agtergrond Postma in Europa en in Nederland opgetree het, sodat sy werksaamhede teen dié breër konteks beoordeel kan word.

* Tweedens word aandag gegee aan Postma se aandeel in die stigting van die eerste Christelike skool in Zwolle waarna sy werksaamhede as lid van die eerste skoolkommissie in oënskou geneem word. Sy onderwysbetrokkenheid in Suid-Afrika word voorts kortliks ondersoek. Die artikel word afgesluit met 'n evaluerende perspektief, waarin die betekenis van sy werk vir SuidAfrika aangedui word.

\section{DIE KULTUUR-HISTORIESE AGTERGROND WAARTEEN POSTMA HOM VIR CHRISTELIKE ONDERWYS BEYWER HET}

Vanweë die Bataafse omwenteling van 1795 het die staat en die plaaslike en streeksowerhede in Nederland mettertyd hulle gereformeerde karakter verloor. Hierdie neutrale staat voer daarna 'n beleid uit wat daarvoor voorsienig maak dat leerlinge van alle "gezindten" gesamentlike onderwys kon ontvang in openbare skole; geen dogma of bepaalde belydenis kon meer in die staatskole verkondig word nie. Baie ouers het gedurende hierdie tye hulle kinders met teensin skole toe gestuur, aangesien die Grondwet van 1806 nie voorsiening gemaak het vir die staatsbekostiging van Christelike skole nie (vgl. Sturm, 1988: 16 e.v.; Nagelhout, 1981:11).

Hierdie liberale gees wat merkbaar was by die Nederlandse owerheid, het deel gevorm van 'n sekulère tendens wat die hele Europa van die vroeë 19de eeu oorspoel het. In die dertigerjare van die 19de eeu het daar egter in Europa ' $n$ beweging, naamlik die Reveil, ontstaan wat hom beywer het vir 'n verdiepte Christelik-godsdienstige lewe, in reaksie teen die koue 18de-eeuse rasionalisme (Sturm, 1988:16 e.v.; De Bruijn, 1989:11-34). 
Ook in Nederland het die ontevredenheid in ortodoks-Protestantse kringe gegroei. Derk Hoksberger, 'n boer uit Wilsum, tussen Zwolle (waar ds. Dirk Postma later sy predikantsbediening in Nederland afgesluit het) en Kampen, was een van die eerstes wat hom na die pen gewend het in protes teen die neutrale onderwysstelsel in Nederland. Hy het daarvoor gepleit dat die mense wat Christelike onderwys op die hart dra, hulle verset moes toon deur hulle kinders uit die staatskole te neem en in eie skole (dit is Christelike skole) te plaas (Nagelhout, 1981:II).

Vir sulke ortodoks-Protestantsgesindes het reformasie van die kerk noodgedwonge ook reformasie van die skool behels. 'n Bekende Nederlandse reformator, Groen van Prinsterer het hom, saam met ander kampvegters vir dieselfde saak, in die stryd gewerp teen die ontkerstening van die openbare skool. Eendersdenkendes het veral in Den Haag en Amsterdam op 'n gereelde basis bymekaar gekom en godsdiensaande. waar binnelandse en ook buitelandse Reveilsprekers opgetree het, gehou. Hierdie byeenkomste het uitgeloop op die vergadering van Christelike Vriende te Amsterdam (1845-1854) onder leiding van die reeds genoemde Groen van Prinsterer, wat ook die hoë pos van Sekretaris van die kabinet van die koning beklee het. Laasgenoemde het 'n deurslaggewende rol gespeel in die latere vestiging van Christelike onderwys in Nederland (Nagelhout, 1981:II; Hofman en Wijnbeek 1925:8-11).

Teen bogenoemde agtergrond kan daar nou nader beweeg word aan die spesifieke tyd en plek waar ds. Dirk Postma 'n betekenisvolle rol gespeel het in die totstandkoming en uitbreiding van Christelike onderwys.

\section{POSTMA SE AANDEEL IN DIE STIGTING VAN DIE EERSTE CHRISTE-} LIKE SKOOL IN ZWOLLE

As die leidende figuur van die Christelike Afgeskeide Gereformeerde Kerk in die provinsie Overijssel het Postma kerk en gemeenskap roepingsgetrou gedien. Hier te Zwolle het hy hom veral vir Christelike onderwys en doeltreffender opleiding vir teologiese studente beywer. Postma se werksaamhede vir die stigting van 'n Christelike skool moet gesien word teen die agtergrond van die aksie van die Christelike Afgeskeide Gereformeerde Kerk ten gunste van Christelike onderwys in Nederland (Nagelhout, 1981:I; Hofman en Wijnbeek, 1925:3-15).

In Augustus 1843 het die kerkraad van die afgeskeide gemeente van Zwolle toestemming van die stadsbestuur gevra om 'n diakonieskool (dit is 'n Christelike skool wat die eiendom van die kerk of diakonie is) op te rig. Hierdie versoek, en 'n soortgelyke versoek aan die Gedeputeerde State in 1844 het nie geslaag nie omdat daar volgens die bogenoemde owerhede geen behoefte aan 'n dergelike skool bestaan 
het nie (Wesseling, 1972:168-169).

Mettertyd het die situasie egter verander, want onder die besef dat die rewolusiegees (rasionalistiese liberalisme wat sy toepassing gevind het in die Franse Rewolusie) nog sterk in Europa leef, en vanweë die afskeiding van België in 1830, het koning Willem II in 1848 ingestem tot 'n hersiening van die Grondwet. In die ontwerpgrondwet word die vryheid van onderwys opgeneem - 'n hersiening wat geïmpliseer het dat die moontlikheid vir die oprigting van staatsgesubsidieerde Christelike skole nou ook 'n werklikheid geword het.

Ook in Zwolle het die kampvegters vir Christelike onderwys in 1848 nuwe moed geskep. Die Christelike Afgeskeide Gereformeerde Gemeente wat in 1835 te Zwolle gestig is, kon sedert sy ontstaanjare nie daarin slaag om 'n Christelike skool tot stand te bring nie. Herhaalde pogings is aangewend deur predikante wat die gemeente van Zwolle bedien het, maar sonder sukses.

Min of meer gedurende hierdie tyd (1849-1850) verskyn Postma op die toneel. Hy was alreeds in kerklike kringe bekend vir sy entoesiasme en ywer ten gunste van Christelike opvoedende onderwys. So het hy in 1842 as skriba van die klassis Warfum deelgeneem aan 'n aksie wat gehandel het oor die verkryging van Christelike onderwys. Verskeie latere klassisse en Provinsiale Sinodes het, met Postma as een van die belangrikste leidende figure, steeds die saak van Christelike onderwys ernstig bepleit. Al was laasgenoemde aksies nie suksesvol nie, het al hierdie pogings van ds. Postma hom toegerus sodat hy dinamies kon optree vir die oprigting van die Christelike skool te Zwolle (Hofman \& Wijnbeek, 1925:I-X; Nagelhout, 1981:I-XXIV; Postma, 1990:26-28 en Van der Vyver, 1958:77-84).

Postma as jong en hardwerkende predikant, het dadelik die vertroue van die kampvegters vir Christelike onderwys in Zwolle gewen. Intussen het Groen van Prinsterer steeds doelgerig en onverpoosd op die hoogste vlak (die Tweede Kamer van die Parlement) voortgegaan met sy stryd in belang van Christelike onderwys. As gevolg van laasgenoemde stryd is die grondwet in 1848 gewysig.

Op die 9de April 1850 is daar opnuut 'n versoekskrif om toestemming tot die oprigting van 'n Christelike skool na die stadhuis te Zwolle gestuur. Hierdie versoekskrif is deur vier persone, waarvan Postma een was, onderteken. Dié versoekskrif het die pad tot by die Gedeputeerde State en die koning geloop en op die 31ste Oktober 1850 ontvang die kommissie van vier volmag om die skool op te rig (Hofman \& Wijnbeek, 1925:9). Postma het persoonlik toegesien dat Groen van Prinsterer die versoekskrif onderteken. 


\section{POSTMA EN SY SKOOLKOMMISSIE SE ARBEID}

Postma het nie net op die hoogste vlak geywer vir Christelike onderwys nie, maar het ook op plaaslike vlak sy volle gewig ingewerp by die vestiging en die uitbou van die nuutgestigte skool.

Die kommissie van vier waarvan die lede hulle met toewyding bemoei het vir die totstandkoming van die Christelike skool te Zwolle, het bestaan uit Dirk Postma, Gerrit Louman, Albertus Bosch en Lambert Pesfink, almal inwoners van die stad Zwolle (Kalsbeek et al., 1904:7).

Direk na die verlof wat die kommissie op 31 Oktober 1850 ontvang het om die skool te stig, het hy ywerig begin werk. Op 6 November 1850 het hy vergader en daarna elke Vrydagaand. Die notule van die eerste aantal vergaderings gee 'n duidelike beeld van die toewyding waarmee die lede hulle selfopgelegde taak aangepak het. So gee die aktes van die eerste skoolwet reeds 'n aanduiding van die karakter wat die skool moes vertoon, naamlik dat veral twee beginsels vir hierdie skool sou geld, by name die handhawing van goeie dissipline gebou op gehoorsaamheid, en leer en lewe by en in die lig van God se Woord.

Die akte wat veral dui op bogenoemde twee beginsels, lui soos volg (Notule, 1850):

Act 4

De eerbied, den kinderen zoo hun betamen, zal onder gezang, gebed en Bijbelsch onderwijs naauwkeurig in acht genomen worden, zoo dat het onstichtelijk zingen, vooral kenbaar aan kind schreeuwen - en cene onecrbiedig houding verboden zijn. De jongmens zullen het gebed staande aanhoren.

Die arbeid wat hierdie kommissie onderneem het, was in alle opsigte waagmoedig. Hofman en Wijnbeek (1925:11-12) beskryf hoe hierdie kommissie te werk gegaan het om die skool in rat te kry. Die kommissielede was onderskeidelik twee bakkers, een sakeman en een predikant. Ten spyte van die feit dat nie een van hulle wetenskaplikopvoedkundig onderlê was nie, het hulle nogtans leerinhoude ter hand geneem, gelees en gekeur volgens die lig wat hulle van Bo ontvang het.

Op 6 Januarie 1851 het Postma hierdie skooltjie met 60 leerlinge geopen - daar was een onderwyser wat met die opvoedende onderwys begin het, naamlik J.H. Weenink. Teen Januarie 1853 was die leerlingtal reeds 144 en 'n aanvang is met 'n aandskool gemaak. Mettertyd het hierdie skool in leerlinggetalle toegeneem en etlike 'dogterskole' is later uit die 'moederskool' in Zwolle gestig (Van der Vyver, 1958:83). 
Die stigting van die Christelike skool in Zwolle was op sigself nie 'n epogmakende daad nie, maar die feit dat juis Postma en sy medestanders gedurende daardie krisistye in Nederland tot so 'n daad oorgegaan het, dra betekenis. Hy het nie net gestry vir die suiwere verkondiging van God se Woord in Nederland nie, maar ook vir Christelike onderwys in Nederland - vir verbondskinders - en dít is op sigself epogmakend.

\section{POSTMA SE ONDERWYSBYDRAE IN SUID-AFRIKA}

Die werk wat Postma in Nederland vir die bevordering van Christelike onderwys gedoen het, het hom voorberei vir grondliggende werk in dieselfde verband in SuidAfrika. Postma vestig hom in 1859 in Suid-Afrika. Gedurende die sestigerjare was die onderwys in Transvaal in ' $n$ benarde toestand, want daar was geen vaste onderwysstelsel nie, en die ouers moes maar self die onderwys van hulle kinders behartig, ten spyte van die feit dat baie ouers self nie goed toegerus was vir so 'n taak nie. Postma het ook hier sy volle gewig ingegooi en enkele hoogtepunte van sy baanbrekerswerk vir die uitbou van Christelike onderwys in Transvaal, is volgens Van der Vyver (1958:419430) en Postma (1944:21-34) die volgende:

* In 1864 word hy aangestel as 'opsiener' van 'n privaatskool te Waterkloof, distrik Rustenburg.

* Op 10 November 1964 open Postma 'n skool te Rustenburg op S.J.P. Kruger se plaas. Dit was die eerste Gereformeerde Kerkskool in SuidAfrika - onder toesig van die plaaslike kerkraad. Ouers van so ver as Potchefstroom het hulle kinders na hierdie skool toe gestuur.

Teen 1866 was die skole van die Kaapprovinsie staatsondersteun en -beheer. Geen dogmatiese onderrig is toegelaat nie, en onder Engelse bewind is skole feitlik geheel en al verengels. Toe Postma hom in 1866 as predikant in Burgersdorp gevestig het, is 'n hele aantal privaatskole in die distrik en omgewing onder sy leiding in stand gehou.

Afgesien van bogenoemde arbeid in Transvaal en die Kaapprovinsie, het hy as outeur, in uitgawes van die Almanak van die Gereformeerde Kerk in Zuid-Afrika (vergelyk bronnelys) en in De Maandbode (vergelyk bronnelys) die volgende Christelike onderwyssake suiwer uit- en toegelig:

* Ouers bly primêr verantwoordelik vir die opvoedende onderwys van hulle kinders.

* Die karakter van die onderwys moes positief Christelik en gereformeerd wees. 
- God se Woord moes onderwys word: dit moes die ganse opvoedende onderwys rig en bepaal.

* Christelike tug moes kenmerkend van die skole wees.

* Ouers moes self die opvoedende onderwys van hulle kinders finansieel onderhou.

Postma het nie net bydraes gelewer vir die totstandkoming en oprigting van Christelike skole in Suid-Afrika nie; hy het ook praktiese hulp aan skole verleen, soos dit vermeld word in De Maandbode van 1876 (Postma, 1876:2): "De buurtschool te Beschuitfontein, gemeente Ventersburg, Kaapkolonie, werd den 22 Junie 1.1. geexamineerd onder het voorzitterschap van ds. D. Postma, daartoe door het school comitee speciaal verzocht."

Op Burgersdorp het die Vrije Christelijke School onder Postma se leiding tot stand gekom. In Die Almanak voor de Gereformeerde Kerk in Zuid-Afrika (Postma, 1886:1920) word die volgende besondere kenmerke van hierdie skool vermeld:

- Bybel en godsdiensonderrig neem 'n eerste plek in die skool se onderwysprogram in.

- Die skoolkommisie stel dit as verpligting dat almal wat die skool besoek, Christelike onderrig sal ontvang.

- Die skool is Christelik "... omdat het onderwijs in eenen Christelijken geest gegeven moet worden, en alles moet doordrongen zijn van den Christelijken Geest".

Postma het aldus Van der Vyver (1958:419 e.v.) besef dat die belangrikste boustene wat in 'n Christelike onderwysstelsel gelê kon word, Christelik-opgeleide onderwysers moes wees. In hierdie verband het hy 'n leidende rol gespeel in die Sinodebesluit van 1869 dat die Teologiese Skool te Burgersdorp só ingerig moes word dat nie net predikante nie, maar ook onderwysers en mense wat 'n breë akademiese opleiding wou ondergaan, dit wel aan die Teologiese Skool kon ontvang. Postma se ideale stel in vooruitsig iets soos 'n Normaalskool vir die opleiding van onderwysers vir laer en sekondere onderwys, dog ook graadopleiding vir teologiese en ander gevorderde studies. Hierdie ideaal van hom is later verwesenlik in die stigting en uitbouing van die Potchefstroomse Universiteit vir Christelike Hoër Onderwys. 


\section{PERSPEKTIEF}

As die werk van Postma en sy geesgenote ten opsigte van Christelike onderwys in Nederland en in Suid-Afrika in oënskou geneem word, kom die volgende perspektiewe na vore:

- Christelike onderwys in Nederland het, voor en gedurende Postma en sy geesgenote se optrede gevaar geloop om te verdwyn. Ondanks vyandige en moeilike omstandighede het laasgenoemde groepie mense, waarvan Postma 'n belangrike leiersfiguur was, hulle ten volle ingewerp in die stryd ten gunste van Christelike onderwys. Gegrond op insigte verkry uit God se Woord en gebou op hulle reformatoriese geloof en belydenis het hulle hulle opvoedings- en opvoedersroeping nagekom - vanaf plaaslike tot op die hoogste vlak. Dit verg geen verdere breedvoerige betoog om aan te dui hoe relevant hierdie perspektief, naamlik om alles in die stryd te werp vir Christelike onderwys in Nederland en in Suid-Afrika, vir die huidige sowel as vir die toekomstige Suid-Afrika is nie. Hier in Suid-Afrika is daar tekens van kritiese en vyandige bedrywighede op staatkundige en onderwysgebied. So toon Van der Walt (1990) aan dat, net soos in ander dele van die wêreld (i.c. Nederland, Australië [vergelyk Fowler, 1991] en Noord-Amerika), Suid-Afrika se (staats-) onderwys gevaar loop om te sekulariseer. Laasgenoemde tendens is veral merkbaar op vakonderwysgebied. Dit is verder algemeen bekend dat Suid-Afrika tans sowel op politiek-konstitutionele as onderwysgebied besig is met sensitiewe onderhandelinge en rasionaliserings. Onderhandelinge in dié verband dreig egter telkens om nie net tot stilstand te kom nie, maar ook om te misluk. Christelike onderwys, wat in sy wese sekularisme en krisisse vanuit 'n ewewigtige regverdigheidsperspektief in behandeling neem, kan ' $n$ groot bydrae lewer tot die moontlike oplossing van bogenoemde probleme, veral met die oog op die toekoms.

Soos Postma en sy geesgenote in die negentiende-eeuse Nederland en SuidAfrika geen steen onaangeroerd gelaat het ter verkryging en bevordering van Christelike onderwys in 'n kritiese en gesekulariseerde wêreld nie, so word Christengelowiges in die huidige Suid-Afrika opgeroep om dienooreenkomstig te handel.

* Soos Postma en sy drie mede-kommissielede hulle destyds in Nederland vir Christelike vakonderwys beywer het, en soos hy later in Suid-Afrika dieselfde doel nagestreef en bevorder het, behoort die Christelike karakter ook alle fasette van Christelike onderwys tans in Suid-Afrika te deursuur.

* Soos bogenoemde Nederlandse kampvegters vir Christelike onderwys, 
behoort alle Christengelowiges, afgesien van die beroepe wat hulle beoefen, hulle onvermoeid en onverpoosd te beywer ten gunste van genoemde onderwys.

* Leer en lewe moet een wees. Verbondsouers behoort konkreet tot dade oor te gaan en Christelike skole te stig.

\section{TEN SLOTTE}

Teen die agtergrond van Postma se ywer en arbeid vir die bevordering van Christelike onderwys in die destydse Nederland en Suid-Afrika, kan dit gestel word dat sy werksaamhede almal wat tans besorg is oor die toekoms van Suid-Afrika, behoort te inspireer tot ewe oorgegewe en visioenêre werksaamhede. Daar moet steeds en toenemend aangedring word op veral dié twee belangrike fasette waarvoor Postma hom so beywer het, naamlik die opleiding van Christenonderwysers en die gee van Christelike onderwys in skole.

\section{BRONNELYS}

BINGLE, P.W. 1954. Dic Gercformecrde Kerk en die onderwys in Suid-Afrika, 1859-1899. Potchefstroom : PUCHO (Verhandeling - M.Ed.)

DE BRUIJN, J. red. 1989. Bepaald gebied. Aspecten van het protestants-christelijk leven in Nederlanden in de jaren 1880-1940. Ten Have : Passage.

FOWLER, S. 1991. A Christian Voice among Students and Scholars. Potchefstroom : PU for CHE.

HOFMAN A.I. \& WIJNBEEK, D. 1925. Hel ontstaan der Ecrste Christelijke School te Zwollc. Zwolle : Electrische Drukkcrij Firma H. Tulp.

KALSBEEK, F., LENS, J. \& MEIJNEN, J.B. 1904. Van strijd en zegen. Gedenkboek van het Christelijk Onderwijs. Leiden : Bock en Stecndrukkerij.

NAGELHOUT, H. 1981. Inleiding by Inventaris van de archieven stukken no. VAO 38 Afdeling Zwolle. Zwollc : Gicmeente-argief.

NOTULE 1850. Kort verslag van het ontstaan en den voortgang der bijzondere school van de ecrste klasje ic Zwollc. Zwollc : Gemeentc-argief.

POSTMA, D. 1876. Schoolnieuws. De Maandbode, 4(5):2, 1 Augustus.

POSTMA, D. 1886. De inwijding van het gebouw, gekocht voor de Theologische School en de Vrije Christelijke School te Burgersdorp (In Alamanak voor de Gereformeerde Kerk in Zuid-Afrika, $17 \mathrm{de}$ jaargang, 1886 . p. 19-20.)

POSTMA, M. 1944. Lewenskets van Vader Dirk Postma (In Postma, A. 1944. 'n Vaste burg is onse God. Potchefstroom : K.J. Bockcfonds. p. 21-34).

POSTMA, W. 1990). Ds. Dirk Postma en Christclik-nasionale onderwys. Die Kerkblad, 93(2854) : 26-28. 
Die betekenis van ds. Dirk Postma se bevordering van Christelike onderwys

STURM, J.C. 1988. Een goede gereformeerde opvoeding. Kampen : J.H. Kok.

VAN DER VYVER, G.C.P. 1958. Professor Dirk Postma 1818-1890. Potchefstroom : Pro Rege Pers Beperk.

VAN DER WALT, J.L. 1990. Christelike onderwys in die praktyk : 'n evaluering van die huidige stand van sake. Koers, 55(2): 247-257, Junie.

WESSELING, J. 1972. De Afscheiding van 1834 in Overijssel. Groningen : De Vuurbaak. 